\title{
Relationship of fish and macroinvertebrate assemblages to environmental factors: Implications for community concordance
}

Dana M. Infante ${ }^{1}$, J. David Allan², Simon Linke ${ }^{3}$, and Richard H. Norris ${ }^{4}$

${ }^{1}$ Department of Fisheries and Wildlife, Michigan State University

East Lansing, Michigan, U.S.A. 48824

${ }^{2}$ School of Natural Resources and Environment, The University of Michigan Ann Arbor, Michigan, U.S.A. 48109

${ }^{3}$ The Ecology Centre, School of Integrative Biology, University of Queensland St. Lucia, QLD 4072, Australia

${ }^{4}$ Cooperative Research Centre for Freshwater Ecology, University of Canberra Belconnen, ACT 2601, Australia

Keywords: stream; land use; geology; habitat; scale; classification

This paper has not been submitted elsewhere in identical or similar form, nor will it be during the first three months after its submission to Hydrobiologia. 


\begin{abstract}
Community concordance describes similarity in distributions and abundances of organisms from different taxonomic groups across a region of interest, with highly concordant communities assumed to respond similarly to major environmental gradients, including anthropogenic stressors. While few studies have explicitly tested for concordance among stream-dwelling organisms, it frequently is assumed that both macroinvertebrates and fish respond in concert to environmental factors, an assumption that has implications for their management. We investigated concordance among fish and macroinvertebrates from tributaries of two catchments in southeastern Michigan having varied landscape characteristics. Classifications of fish and macroinvertebrate assemblages resulted in groups distinguished by differences in taxonomic characteristics, functional traits, and stressor tolerance of their respective dominant taxa. Biological groups were associated with principal landscape gradients of the study region, which ranged from forests and wetlands on coarse surficial geology to agricultural lands on finer, more impervious surficial geology. Measures of stream habitat indicated more stable stream flows and greater heterogeneity of conditions at site groups with catchments comprised of forests and wetlands on the coarsest geology, but did not distinguish well among remaining site groups, suggesting that habitat degradation may not be the driving mechanism leading to differences in groups. Despite broadly similar interpretations of relationships of site groups with landscape characteristics for both fish and macroinvertebrates, examination of site representation within groups indicated weak community concordance. Our results suggest that explicit responses of fish and macroinvertebrates to landscape factors vary, due to potential differences in their susceptibility to controls or to differences in the scale at which landscape factors influence these organisms.
\end{abstract}




\section{Introduction}

The distribution and abundance of organisms in fluvial systems are influenced by numerous drivers operating at multiple spatial scales (Vannote et al., 1980; Tonn et al., 1990; Poff, 1997). Large-scale controls include biogeographical constraints, which determine the potential species pool for a given region, as well as landscape features including topography, geology, and climate, which can influence smaller-scale factors important to biota such as type and availability of energy sources, water quality, and physical habitat (Poff, 1997; Sneldor \& Biggs, 2002). Increasingly, researchers recognize that human activities at the landscape scale can impact biological assemblages of streams and that this control results from landscape's indirect effects on factors that influence biota at smaller spatial scales (Allan, 2004; King et al., 2005; Infante et al., 2006). Consequently, protecting aquatic systems from anthropogenic impacts depends not only on revealing causes of impairment, but also on anticipating the stream biota's specific responses to stressors operating at multiple scales. Recent attempts to meet these needs include studies identifying ecological indicator metrics (e.g., Karr, 1991; Wright, 1995; Barbour et al., 1999; Norris \& Hawkins, 2000) and efforts comparing effects of anthropogenic land use at various scales from the stream reach to the entire catchment (e.g., Roth et al., 1996; Lammert \& Allan, 1999; Sponseller et al., 2001; Wang et al., 2001).

Whether large-scale or local drivers are found to have greater influence over the distribution and abundance of fluvial organisms varies with the scale of investigation. In studies across large regions, factors such as climate, geology, and topography may be primary (Legendre \& Legendre, 1984; Whittier et al., 1988; Van Sickle \& Hughes, 2000). However, in studies at smaller scales, local conditions may be paramount (Townsend et al., 2003; Wang et al., 2003) due in part to relatively less variation in key landscape drivers across small regions. This 
accords with the view that large-scale and then smaller-scale factors operate as hierarchical filters in determining assemblage composition at a site (Tonn et al., 1990; Poff, 1997; Sneldor \& Biggs, 2002). For example, a model developed for native fishes of the North Platte River that used large scale biogeographical variables followed by local abiotic and biotic variables effectively predicted local assemblages of river systems (Quist et al., 2005). In the Taieri River basin, South Island, New Zealand, environmental variables that best accounted for variation in macroinvertebrate assemblages were primarily those at the catchment scale, although the presence of pasture land in the riparian zone was also influential (Townsend et al., 2003).

While the studies above suggest how fluvial fish and macroinvertebrate assemblages may be responding to hierarchical filters, a question that few studies have addressed is whether or not different groups of organisms respond in parallel to these filters. Community concordance describes the degree to which patterns in assemblage structure across a given region are similar among different taxonomic groups (Paszkowski \& Tonn, 2000). Concordance would be expected if different taxa exhibit similar responses to major environmental gradients, including anthropogenic stressors, and would support the use of one taxonomic group as a surrogate for others. While few studies have explicitly tested for concordance among stream-dwelling organisms, it frequently is assumed that both macroinvertebrates and fish respond similarly to environmental factors operating at various scales (e.g., Kilgour \& Barton, 1999). Evidence in support of this expectation, however, is contradictory. In the case of the Taieri, strongly dispersing invertebrates showed a weaker relationship to large-scale landscape variables than did invertebrates with poor dispersal abilities, potentially due to their greater ability to overcome geographic barriers (Townsend et al., 2003). Also, community classifications were not found to be concordant across headwater streams in a near-pristine area of Finland (Paavola et al., 2003). 
Patterns in macroinvertebrate distributions were related mainly to stream size and $\mathrm{pH}$; bryophytes responded to nutrient content and physical habitat variability; and fish were best correlated with stream depth, substrate size, and water oxygen concentration. A final example comes from a recent study by Paavola et al. (2006) that explicitly addressed the role of spatial scale in perceived degrees of concordance. Their results related concordance among fish, macroinvertebrates, and bryophytes to the scale of investigation: across sites from multiple drainages, organism groups showed similar responses to environmental variables, while within drainages, groups showed less concordance. They attributed this to the fact that organisms may be responding similarly to regional environmental factors but differently to local conditions. Further, they suggested that for studies occurring at smaller spatial scales, concordance may be observed if organisms respond similarly to a dominant environmental gradient, such as a disturbance like anthropogenic land use.

Because environmental assessments are often based on the response of a single taxonomic group to anthropogenic stressors and because actions taken to protect or restore fluvial systems often occur at relatively small spatial scales (i.e., individual subcatchments or reaches), understanding potential differences in the response of fish vs. macroinvertebrates to stressors, as well as the scale at which stressors originate, is critical for improved assessment and management. Based on those needs, this study will evaluate the response of fish and macroinvertebrates to dominant landscape gradients across a relatively small region of southeastern Michigan, comparing their responses to environmental factors to explore concordance among these taxonomic groups.

Our study has three objectives. First, we determine whether classifications of fish vs. macroinvertebrate assemblages yield groups of sites with distinct, biologically-interpretable 
characteristics by considering dominant organisms and their functional traits for each resulting group. We next consider whether the separate classifications of fish and macroinvertebrates yield similar groups of sites. Analogous interpretations of fish and macroinvertebrate site groups having similar site membership would lend support to the question of their concordance in the study region. Finally, we consider relationships of fish and macroinvertebrate site groups to catchment and buffer landscape characteristics and physical habitat of study sites. Considering potential differences in associations between biological groups and environmental variables provides additional insights into concordance within the region and also into the role of landscape factors in structuring these relationships.

\section{Methods}

Study region

Located in southeastern Michigan (Figure 1), the Huron and Raisin River basins are of similar size, draining areas of 2330 and $2780 \mathrm{~km}^{2}$, respectively. The upper portions of both basins lie in an area of relatively coarse surficial geology shaped by glacial activity and include ground and end moraines, outwash plains, and areas of ice contact. Towards their outlets, the basins drop onto the impervious sand and clay lakeplains adjacent to Lake Erie (Farrand \& Bell, 1982). Approximately $28 \%$ of the Huron drainage is urbanized, while only $12 \%$ of the Raisin drainage is urban land (Cifaldi et al., 2004). The Huron also contains almost twice the area of forest and wetlands as the Raisin (40 vs. 22\%). However, agriculture dominates the Raisin's landscape, with $63 \%$ of the basin devoted to agriculture compared to $25 \%$ of the Huron's landscape.

Subcatchment and site selection 
Forty-six subcatchments draining primarily second-order streams were selected for study from within the historically-glaciated portions of the Huron and Raisin River basins. Site selection emphasized variation in land cover within the region; however, we excluded subcatchments with high levels of commercial or industrial development. Within each subcatchment, we selected a single site for study at least $1 \mathrm{~km}$ above the stream tributary's confluence with a larger tributary. Biological assemblages and physical habitat were characterized by sampling a $100 \mathrm{~m}$ reach of each study stream.

\section{Biological data}

Fish were collected during the summers of 1999 and 2000 using three-pass electrofishing depletion surveys in blocked reaches. All fish except for two native lamprey were identified to species and recorded as total number captured per $100 \mathrm{~m}$ reach. Macroinvertebrates were collected during the spring of 2000 and 2001 with $250-\mu m$ mesh D-nets by sampling all habitat types present in proportion to their relative abundance. A subsample of 500-700 macroinvertebrates from each site was identified to the lowest practical taxonomic level. Noninsect taxa were typically identified to order or family, and remaining insect taxa were identified to genus, with exceptions including Chironomidae and Ceratopogonidae which were identified to family (Wood, 2002).

\section{Physical habitat}

Physical habitat features of the study reaches were summarized by 22 variables grouped into four categories. Channel shape descriptors, including reach averages for bankfull and low flow channel width, depth, and cross-sectional area were determined following methods described in Infante et al. (2006). Pebble counts were performed through the thalweg channel, and quantitative measures of substrate considered in analysis included median particle size and 
proportions of fines less than $2 \mathrm{~mm}$ in diameter, gravel, cobble, and coarse substrate greater than $180 \mathrm{~mm}$ in diameter. Frequency of occurrence of riffle habitat and wood were summarized from counts at $5 \mathrm{~m}$ intervals through stream reaches. Finally, physical habitat was assessed using a visual habitat assessment protocol (Michigan Department of Environmental Quality 1997). This protocol scores overall habitat quality by combining scores from nine individual components including amount and diversity of available cover; substrate embeddedness; variability in velocity and depth; flow stability; bottom deposition and sedimentation; diversity of pools, riffles, runs and bends; bank stability; bank vegetation stability; and streamside cover. For analysis, we considered both the total habitat score and scores for individual metrics.

\section{Landscape variables}

Data describing the landscape within subcatchments were obtained using a Geographic Information System (GIS). Surficial geology of each subcatchment, determined from maps compiled by Farrand \& Bell (1982), was summarized into two categories reflecting different hydraulic conductivities. The measure referred to as “coarse geology” includes the sum of coarse end and ground moraine, ice contact, and outwash - all geologic types that promote a stable supply of groundwater to streams. The variable referred to as "fine geology" is the sum of proportions of fine end and ground moraines and clay and sand lakeplain, geologic types that tend to have low permeability and thus encourage greater amounts of surface runoff.

Land use was quantified for each study subcatchment and for $200 \mathrm{~m}$ wide buffers for the length of the streams based primarily on 1978 data (Michigan Resource Information System (MIRIS), 1978). Inspection of 2001 aerial photography verified the accuracy of the earlier land cover classification for agricultural and natural (forest, wetland) categories. Urban land use was 
Infante et al.

updated with aerial photos from 1995 for the majority of the study region and from 1998 for Lenawee County (Cifaldi et al., 2004).

Data analysis

Analyses were based on relative abundances of fish and macroinvertebrates. Rare taxa, defined as those that occurred at fewer than $10 \%$ of sites sampled (four study sites), were excluded from analysis because their presence can result in excessive splitting in cluster analysis (Hawkins et al., 2000). This resulted in inclusion of 74 macroinvertebrate taxa (out of 182 total) and 26 fish species (out of 41 total). Before analysis, physical data were log-transformed, as were biological data to down-weight the influence of highly abundant taxa (Norris \& Georges, 1993).

To consider biological characteristics shared by groups of sites, we classified sites based on homogeneity of their faunal composition. Classification was performed in PATN (Belbin, 1992) using the flexible unweighted pair-groups and arithmetic averages (UPGMA) fusion strategy recommended by Belbin \& McDonald (1993), with flexible-Beta set at -0.1 to optimize the hierarchy. This approach equally weights site groups during the agglomerative clustering process, regardless of their size (Lance \& Williams, 1967). The Bray-Curtis associating measure was used for the dissimilarity matrix because it ignores joint absences, which are predominant in taxa matrices (Faith et al., 1987). Classifications were performed separately for fish and macroinvertebrates.

To identify dominant environmental variables and taxa associated with sites, we first used hybrid multidimensional scaling (HMDS, Faith et al., 1987) in PATN (Belbin, 1992) to ordinate sites based on their fish and macroinvertebrate assemblages. A Monte Carlo simulation (MCSS with 100 permutations, Belbin, 1992) was performed on the resulting ordinations to 
determine the probability that ordinations explained structure in the data that might have occurred by chance alone (Faith, 1990). Relationships between individual taxa and positions of sites in the respective ordination spaces generated for fish and macroinvertebrates were then determined using principal axis correlation (PCC, Belbin, 1992, see also Faith \& Norris, 1989). Using PCC, we also determined relationships between environmental variables and positions of sites. Monte Carlo significance tests (MCAO with 100 permutations, Belbin, 1992) were performed to test the significance of correlation values obtained in the PCC procedure so that those variables most closely associated with the structure of the biological assemblages could be selected. Only those environmental variables and fish species with a significance of 0.05 or less were used for interpretation. For macroinvertebrate taxa, those with a significance of 0.005 or less were considered due to the large number of taxa selected at the lower level of significance. We next used multiple strategies to determine biological and physical characteristics of individual site groups. First, we identified biological characteristics of groups by comparing average relative abundances of taxa identified by the PCC for each group. Also, relative abundances of common taxa were summarized by their functional traits and averaged across site groups to lend additional support to biological interpretations. For this step, macroinvertebrate trait assignments were made from information summarized by Vieira et al. (2006) and fish trait assignments were made from information summarized by Goldstein \& Meador (2004) and Poff \& Allan (1995). Finally, we determined dominant physical characteristics by comparing average values of PCC-identified habitat and landscape variables across groups.

Because classification analysis has limitations linked to offsets, chaining effects, and input order, as well as theoretical concerns about the occurrence of biological organisms in distinct groupings (Podani, 1997; Linke et al., 2005), the corroboration of results by multiple 
analysis techniques lends confidence to the conclusions. To gain additional insights into concordance of fish and macroinvertebrates, we compared dissimilarity of taxa matrices using a Mantel's test in PC-ORD 4.0 (McCune \& Mefford, 1997). We also considered patterns in site inclusion in fish vs. macroinvertebrate groupings with contingency analysis performed in SPSS 15.0.

\section{Results}

Site groupings based on macroinvertebrate assemblages

Sites were clustered into four groups based on similarity in relative abundances of macroinvertebrate taxa, and 23 taxa were identified by PCC as being significantly associated with variation in macroinvertebrate assemblages of the study sites (Table 1). Taxa with highest average relative abundances for sites in Group 1 included Gammarus (Amphipoda) and oligochaetes. Chironomids, which were the most abundant invertebrate collected from all study sites, and gastropods reached their highest average relative abundances at Group 2 sites, and none of the Group 2 sites supported either of the two genera of Plecoptera identified by PCC. Group 3 had higher median taxa richness than sites of any other group (Figure 2), and 13 taxa reached their highest average relative abundances at Group 3 sites, including eight genera of Ephemeroptera, Plecoptera, and Trichoptera (EPT taxa). Only one taxon, Simulium (Simuliidae), was most abundant at Group 4 sites.

Comparisons of functional traits of all common macroinvertebrate taxa including tolerance to stressors and habit and trophic preferences provide additional insights into group differences. With greater taxonomic richness, Group 3 sites also had higher median relative abundance of macroinvertebrates with low tolerance to stressors than other site groups (Figures 2 and 3, respectively). Also, sprawlers, swimmers, and clingers were more abundant at Group 3 
sites, as were shredders, scraper-grazers, and predators (Figure 4). In contrast, organisms that were classified as burrowers and collector-gatherers (including chironomids) were most abundant at Group 2 sites where they averaged more than $80 \%$ of organisms collected; sites in Group 2 also had the lowest abundances of low-tolerance organisms (Figure 3). Sites in Group 1 had high abundances of crawlers and omnivores, reflecting the dominance of amphipods at the sites (Figure 4). Similarly, sites in Group 4 were dominated by collector-filterers, which include simuliids.

\section{Environmental variables characterizing macroinvertebrate clusters}

The PCC identified seven habitat variables that were significantly related to variation in macroinvertebrate assemblages (Table 2). These included descriptors of habitat complexity (variability in velocity and depth and a diversity of pools, riffles, runs and bends through sample reaches), descriptors of hydrology (channel incision, metrics scoring flow and bank stability), and embeddedness of stream bed substrate. Average scores for habitat assessment metrics were highest across Group 3 sites, and channel incision was lowest, together indicating more complex habitat, more stable hydrology, and lower embeddedness at the Group 3 sites compared to other groups. Sites in Group 2 had lowest average scores for all of the visual metrics estimating habitat quality, while scores for sites in Groups 1 and 4 were mid-range, with Group 1 sites generally having slightly higher scores than Group 4 sites.

Seven landscape variables were also identified by PCC that were significantly related to macroinvertebrate assemblages, and trends across site groups emphasized interrelationships in natural and anthropogenic landscape gradients throughout the study region. Sites in Group 3, for example, had highest percentages of both undeveloped lands (including wetlands and forests) and coarse surficial geology in their catchments (Table 2). In contrast, Group 2 sites had the 
Infante et al.

finest surficial geology and the least undeveloped lands. For Groups 1 and 4, permeability of surficial geology and natural landscape cover were mid-range compared to Groups 2 and 3. Site groupings based on fish assemblages

Sites were clustered into five groups based on similarity in relative abundances of fish species, and PCC identified seven species that were significantly associated with variation among assemblages (Table 3). Sites of Fish Group 1 supported the highest average relative abundance of Rhinichthys atratulus; while present at Group 2 sites, these fish were not collected from sites in other groups. Etheostoma nigrum and Campostoma anomalum were more abundant at Group 2 sites compared to sites in other groups, and Group 4 sites supported higher abundances of two centrarchids, Lepomis macrochirus and L. gibbosus. Cottus bairdi dominated the assemblages of the Group 5 sites, averaging 91\% of all individuals captured, and Luxilus cornutus averaged 9\% of individuals collected from Group 3 sites. Species richness varied across Groups 1, 4, and 5, but Groups 2 and 3 had similar and higher median richness (Figure 2).

As with macroinvertebrates, comparisons of functional traits of common fish species also suggest ecological differences among site groups. Group 2 sites supported common assemblages with a wider range of trophic preferences than assemblages of other sites (Figure 5). Also, Groups 2 and 3 supported assemblages with more diverse substrate preferences than fish from other site groups. In terms of habitat specialization, Group 3 sites had more fish preferring riffles than other groups, while fish preferring pools and backwater dominated Group 4 sites. Group 4 sites also supported the most fish preferring vegetation and the most with variable substrate preferences. Finally, in terms of tolerance to stressors, sites in Group 3 supported the highest median abundance of fish with low tolerance for stressors (Figure 3). Environmental variables characterizing fish clusters 
Infante et al.

PCC identified three habitat variables significantly related to variation in fish assemblages (Table 4). First, channel fit, a variable calculated as the ratio of bankfull to low flow stream widths, is an estimate of the fit of the low flow hydraulics to the available channel cross section (Infante et al. 2006), and streams with larger ratios may have more variable flow regimes than similarly-sized streams with smaller ratios. Average channel fit values were lowest at Group 3 sites and highest at Group 5 sites, indicating that conditions were hydraulically more favorable at Group 3 sites and least favorable at Group 5 sites. The range in group averages of the second variable identified by the PCC, bank stability, followed the same trend as channel fit; stream banks were most stable for sites of Group 3 and least stable for Group 5 sites. The third variable identified by the PCC was a visual metric scoring the diversity of pools, riffles, runs, and bends throughout stream reaches. Group 3 sites had the highest score for diversity of habitat units, and Group 5 sites, the least.

As with macroinvertebrates, the landscape variables identified by PCC related to variation in fish assemblages (coarse surficial geology and agriculture, Table 4) show the link between geology and land use across the study region. Sites in Group 3 had the highest percentages of coarse surficial geology and the least agriculture in their catchments, while sites in Groups 2 and 5 had comparatively fine surficial catchment geology and more agriculture. Concordance among fish and macroinvertebrate assemblages

Mantel's statistic $(r=0.083)$ indicated that the dissimilarity matrix of fish relative abundances across study sites was not correlated with that of macroinvertebrates. Also, using contingency analysis, site overlap in fish and macroinvertebrate groups was not strong, even when considering groups with similar characteristics (Table 5). For example, macroinvertebrate Group 3, characterized by high median taxa richness, the greatest number of intolerant taxa, and 
highest site-average percentages of catchment coarse surficial geology and natural land, included 19 sites. Only seven of these sites were included in Fish Group 3 which had the most closely matching characteristics (high species richness and numbers of intolerant fish, highest siteaverage percentages of catchment coarse surficial geology, and lowest of agricultural land).

While all seven sites of Fish Group 3 were included in Macroinvertebrate Group 3, the remaining 12 sites were included in Fish Groups 1, 2, and 4. Similarly, the 18 sites of Fish Group 2, with the most agriculture and most fine surficial geology in their catchments, were contained within all four macroinvertebrate groups. Together, Mantel's test and consideration of the extent of correspondence of sites between fish and macroinvertebrate groups support the interpretation that these two organismal groups, which are widely used to evaluate stream condition, exhibit at best weak concordance across our study region.

\section{Discussion}

Cluster analyses of fish and macroinvertebrate assemblages from 46 stream sites in southeastern Michigan resulted in distinct biological groups characterized by differences in dominant taxa, taxa richness, and functional traits of organisms including their trophic niches, habitat preferences, and tolerance to stressors. Within taxonomic categories, biological differences were related to differences in natural and anthropogenic landscape factors. For both fish and macroinvertebrates, biological assemblages characterizing sites draining catchments with more agricultural land use and finer surficial geology generally had less taxonomic diversity, had less diversity in functional traits, and were more tolerant of stressors than assemblages of sites draining catchments with more natural lands (i.e., forests, wetlands) and coarser surficial geology. Also, PCC identified patterns in physical habitat suggestive of mechanistic relationships between landscape factors and biology: habitat conditions at sites 
draining catchments with more anthropogenic land use and fine surficial geology were generally sub-optimal, with more variable flow regimes and less habitat heterogeneity, compared to sites in catchments with more natural lands and coarse geology.

Despite similarities in interpretations of biological groups derived for both sets of organisms and in their relationships with catchment landscape attributes and physical habitat of sites, site overlap between fish and macroinvertebrate groups sharing similar interpretations was not strong. As shown by Mantel's test, distributions of fish across study sites were not significantly correlated with distributions of macroinvertebrates. Also, as suggested by the contingency table, the arrangement of sites into groups revealed limited biological correspondence among sites. Together, these results indicate weak community concordance and suggest that, within our study region, explicit responses of fish and macroinvertebrates to landscape factors differ, indicating potential differences in their susceptibility to landscape influences or to differences in the scale at which landscape factors affect these organisms. Response of biological assemblages to landscape features

Although PCC identified different individual landscape variables that explained variation in fish vs. macroinvertebrate assemblages, the variables represented the same general gradient in landscape conditions for both taxonomic groups. The extent of undeveloped lands, including forests and wetlands, and catchment surficial geology were identified by PCC as explaining patterns in macroinvertebrates, while variation in extent of agriculture and coarse catchment surficial geology were identified for fish. However, across our study region, patterns of land use and surficial geology are strongly inter-correlated with one another (Diana et al., 2006). Agricultural land use is the dominant anthropogenic landscape gradient and occurs most commonly in catchments comprised of fine surficial geology, whereas undeveloped lands are 
more common in catchments comprised of coarser geology. This is likely due to the fact that finer, less pervious surficial geology is more suitable for agriculture than coarser, more pervious areas of the study region (Allan, 2004). Consequently, we conclude that fish and macroinvertebrate assemblages respond to the same gradient in landscape conditions, which ranges from undeveloped lands on coarse, well-drained surficial geology to agricultural lands on finer, more impervious surficial geology.

The fish and macroinvertebrate site groups with the least amount of catchment and buffer agriculture (i.e., most forest and wetlands) and the coarsest surficial geology had biological attributes suggestive of least impacted environments. Macroinvertebrate Group 3 and Fish Group 2 both had high median taxa richness compared to sites in other groups, supported comparatively large numbers of organisms with low tolerance to stressors, and generally supported organisms with more varied habit and trophic preferences. This result is consistent with expectations suggested by various multimetric approaches for assessing biological integrity: that least impacted environments should support biological assemblages with greater taxonomic and functional diversity than those of impacted environments (Hilsenhoff, 1982; Lyons, 1992; Lyons et al., 2001).

In contrast, fish and macroinvertebrate site groups with higher amounts of catchment agriculture and finer surficial geology showed signs of faunal degradation. For example, sites of Macroinvertebrate Group 4, with less than half as much coarse surficial geology in their catchments as other site groups, had larval blackflies (Simuliidae) as their only dominant taxon, and these organisms were three times as common at Group 4 sites as in other site groups. Chironomids dominated the assemblages of sites in Macroinvertebrate Group 2 (82\%, Table 1) which had the least natural land and the finest catchment surficial geology; this group also had 
the lowest median macroinvertebrate taxa richness of all groups. Fish Group 5, with comparatively low amounts of coarse surficial geology and high amounts of agriculture, also supported the fewest fish species of all groups. However, while having similar landscape characteristics as Group 5, Fish Group 2 had a median species richness equivalent to that of Fish Group 3, implying that decreased species richness may not always be a resulting impact of agricultural land use on fish assemblages. Further, these results suggest that fish and macroinvertebrate assemblages may be responding to stressors associated with agricultural land use in different ways. Despite a median taxa richness similar to Fish Group 3, assemblages of sites in Fish Group 2 generally supported more fish that were tolerant of stressors (Figure 3). While leading to a decrease in numbers of intolerant fish species, agricultural land use may have resulted in favorable conditions for tolerant fish species. A loss of intolerant fish accompanied by a gain in tolerant, native fish has been identified as a potential factor contributing to the homogenization of biotic assemblages in freshwater systems (Scott \& Helfman, 2001; Olden \& Poff, 2004). This trend has been documented for fish assemblages impacted by urban land use in the Etowah River Basin, Georgia (Walters et al., 2003) and described as occurring throughout the southeastern United States (Scott \& Helfman, 2001).

Numerous studies document the departure of fluvial biological assemblages from reference conditions with increasing extent of agricultural land within the catchment (Richards et al., 1996; Roth et al., 1996; Stewart et al., 2001; Townsend et al., 2003; Rios \& Bailey, 2006). However, the percentage of agricultural land use at which impacts are observed varies widely. Negative effects have been associated with as little as 20\% buffer agriculture (Fitzpatrick et al., 2001), while other studies have founds its effects to be minimal below 30\% (Quinn, 2000) or even 50\% agricultural land in the catchment (Wang et al., 1997; Meador \& Goldstein, 2003). 
Infante et al.

While the influence of agriculture may not be adequately captured by a simple percentage, the ecological effects of agriculture generally are apparent when it exceeds $50 \%$ of catchment area (Allan, 2004).

Landscape's influence on biota via effects on intermediate factors

One of the ways in which landscape factors may be influencing fish and macroinvertebrates of our study region is through effects on the physical stream environment, including direct effects on flow regimes and related, indirect effects on physical habitat features. For groups of sites with a greater extent of catchment agriculture and fine surficial geology, measures of channel incision (for macroinvertebrate groups) and channel fit (for fish groups) indicated more variable flow regimes than sites draining natural landscapes with greater amounts of coarse geology. Also, as shown for both fish and macroinvertebrate groups, sites in catchments with more agriculture and fine geology had relatively less habitat heterogeneity as indicated by habitat assessment metrics. However, differences in habitat features across site groups considered degraded based on biological characteristics were generally not pronounced. Although Fish Groups 1, 2, 4, and 5 and Macroinvertebrate Groups 1, 2, and 4 received lower total scores for habitat assessment metrics than their counterparts draining the most natural land and coarsest geology, only Macroinvertebrate Group 2, with the lowest average amount of coarse surficial geology and a low percentage of undeveloped land received a substantially lower score for flow stability; bank stability; and diversity in pools, riffles, runs, and bends than other site groups. This broad similarity in habitat may result from the interrelationship between catchment agriculture and fine surficial geology in the region and to similar effects that these landscape factors can have on stream environments. For example, both tillage and drainage practices in agricultural regions and greater imperviousness associated with finer surficial geology can 
encourage surface runoff. Consequently, storm flows may be more powerful and more erosive, encouraging siltation and potentially less habitat heterogeneity in agricultural catchments or catchments with finer surficial geology.

Comparatively stable flows and greater physical habitat heterogeneity help to distinguish the two site groups with the most natural land and coarse surficial geology from remaining site groups; however, differences in habitat features across these remaining groups appear insufficient to fully account for the differences in biological assemblages that result from the classification. Other factors not accounted for by this study may be contributing to differences in assemblages, perhaps including altered thermal regimes, elevated nutrient levels, or contamination by pesticides or organic matter resulting from agricultural landscapes (Lenat, 1984; Osborne \& Wiley, 1988; Johnson et al., 1997). Yoder \& Rankin (2004) report an intriguing paradox from similar studies in Ohio that support this conclusion. While habitat measures were the best predictors of spatial variation in an Index of Biotic Integrity (IBI) for fish assemblages within their study region, sites with 20 years of monitoring experienced improvement in the IBI but not in habitat quality, suggesting that improvements in water quality may have benefited the biota of the region even when habitat remained sub-optimal.

\section{Community concordance}

Although the biological assemblages of the Huron and Raisin formed distinct groups that could be related to ranges in landscape condition, results from the contingency analysis indicated weak concordance between site groups formed from the two sets of organisms, suggesting that within this study region, fish and macroinvertebrate assemblages are responding to landscape factors in discernibly different ways. This weak concordance could reflect scale-dependent differences in the way that fish and macroinvertebrates are influenced by disturbances resulting 
from agricultural landscapes or by the effects of fine surficial geology. That macroinvertebrates may respond to local-scale habitat conditions while fish are more strongly influenced by impairment at a larger scale is a common inference in stream ecology (e.g., Kilgour \& Barton, 1999), arising from key differences in characteristics of these two groups of organisms. Compared to fish, macroinvertebrates may respond primarily to localized stressors because of shorter life cycles and more limited mobility during stages when they are restricted to stream environments. Fish may have a greater capacity to avoid localized disturbances, moving out of impacted areas or into refuges of good habitat for certain portions of their life cycle (Schlosser, 1995; Fausch et al., 2002).

Several studies support the view that fish and macroinvertebrates are influenced by environmental factors operating at different scales. In an investigation of lakes in the northeastern U.S.A, Allen et al. (1999) found that birds, fish, and macroinvertebrates were associated with large-scale measures including climate and land cover but that diatoms and zooplankton responded more strongly to local-scale variation including $\mathrm{pH}$ and lake depth. Townsend et al. (2003) showed that macroinvertebrate assemblages in New Zealand streams, while influenced by catchment scale measures, were more strongly affected by anthropogenic land uses measured at smaller scales, and that geographical location was most strongly correlated with fish assemblage composition throughout the region. Johnson \& Goedkoop (2002) showed that, while large-scale factors were important, local-scale measures explained more variance in littoral macroinvertebrate assemblages. In contrast, the distribution of stream fish in Portugal indicated the greater importance of large-scale environmental factors compared with microhabitat characteristics (Magalhaes et al., 2002). Recently, a study by Burcher et al. (2007) showed that fish in North Carolina streams were more closely associated with alterations in 
stream reach morphology resulting from landscape disturbance than macroinvertebrates which were associated with alterations in erosional substrate measured at the habitat patch scale. In the present study, PCC analysis showed macroinvertebrate assemblages to be significantly associated with three times as many site-specific local scale habitat metrics as were fish.

We suggest that the scale of this study influenced the outcome of our investigation of community concordance as well as the degree to which we associated biological groups with gradients in landscape factors. This finding is supported by a recent work by Paavola et al., (2006), who showed that concordance among fish, macroinvertebrates, and bryophytes was stronger across multiple river basins spanning several ecological regions and weaker throughout an individual watershed. Based on literature reviewed above, it appears that concordance between different taxonomic groups in their response to environmental gradients may be most readily detected in studies that span a broad geographic region, allowing for strong gradients in climate, natural vegetation patterns, and geology. Numerous classifications performed across large regions have identified natural factors important to stream biota that varied little in this study of the Huron and Raisin River basins, including climate and vegetation patterns in Quebec (Legendre \& Legendre, 1984); geology, soils and vegetation in Oregon (Whittier et al., 1988; Van Sickle \& Hughes, 2000); and geology, soils and vegetation in Kansas (Hawkes et al., 1986). With differences in these large-scale drivers minimized, the greatest source of variation in the present study was due to local landscape features, allowing for the close association of the biota with these gradients.

\section{Acknowledgements}

We wish to thank the many individuals involved with data collection and processing including Matt Diana, Janelle Francis, Diana Karwan, Eric Sokol, Jo Wilhelm, and Mahya 
Infante et al.

Wood. This research was supported by a grant from the National Science Foundation's Water and Watersheds Program. 
Infante et al.

\section{Literature Cited}

Allan, J. D., 2004. Landscapes and riverscapes: The influence of land use on stream ecosystems. Annual Review of Ecology, Evolution, and Systematics 35: 257-284.

Allen, A. P., T. R. Whittier, D. P. Larsen, P. R. Kaufmann, R. J. O’Connor, R. M. Hughes, R. S. Stemberger, S. S. Dixit, R. O. Brinkhurst, A. T. Herlihy \& S. G. Paulsen, 1999. Concordance of taxonomic composition patterns across multiple lake assemblages: Effects of scale, body size, and land use. Canadian Journal of Fisheries and Aquatic Sciences 56: 2029-2040.

Barbour, M. T., B. D. Gerritsen, B. D. Snyder \& J. B Stribling, 1999. Rapid bioassessment protocols for use in streams and wadeable rives: Periphyton, benthic macroinvertebrates and fish. Second Edition. EPA 841-8-99-002. US Environmental Protection Agency, Office of Water, Washington D.C.

Belbin, L., 1992. PATN (Pattern Analysis Package) Technical Reference. Commonwealth Scientific and Industrial Research Organization, Division of Wildlife and Ecology, Canberra, Australia.

Belbin, L. \& C. McDonald, 1993. Comparing three classification strategies for use in ecology. Journal of Vegetation Science 4: 341-348.

Burcher, C. L., H. M. Valett, \& E. F. Benfield, 2007. The land-cover cascade: Relationships coupling land and water. Ecology 88: 228-242.

Cifaldi, R. L., J. D. Allan, J. D. Duh \& D. G. Brown, 2004. Spatial patterns in land cover of exurbanizing watersheds in southeastern Michigan. Landscape and Urban Planning 66: 107-123. 
Diana, M., J. D. Allan \& D. M. Infante, 2006. The influence of physical habitat and land use on stream fish assemblages in southeast Michigan In R. M. Hughes, L. Wang \& P. W. Seelbach (eds), Influences of landscapes on stream habitats and biological assemblages. American Fisheries Society, Bethesda, Maryland.

Faith, D. P., 1990. Benthic macroinvertebrates in biological surveillance: Monte Carlo significance tests on functional groups’ responses to environmental gradients. Environmental Monitoring and Assessment 14: 247-264.

Faith, D. P., P. R. Minchin \& L. Belbin, 1987. Compositional dissimilarity as a robust measure of ecological distance. Vegetatio 69: 57-68.

Faith, D. P. \& R. H. Norris, 1989. Correlation of environmental variables with patterns of distribution and abundance of common and rare freshwater macroinvertebrates. Biological Conservation 50: 77-98.

Farrand, W. R. \& D. L. Bell, 1982. Quaternary geology of southern Michigan (map). Department of Geological Sciences, University of Michigan, Ann Arbor, Michigan.

Fausch, K. D., C. E. Torgersen, C. V. Baxter \& H. W. Li, 2002. Landscapes to riverscapes: Bridging the gap between research and conservation of stream fishes. BioScience 52: 483-498.

Fitzpatrick, F. A., B. C. Scudder, B. N. Lenz \& D. J. Sullivan, 2001. Effects of multi-scale environmental characteristics on agricultural stream biota in eastern Wisconsin. Journal of the American Water Resources Association 37: 1489-1507.

Goldstein, R. M. \& M. R. Meador, 2004. Comparisons of fish species traits from small streams to large rivers. Transactions of the American Fisheries Society 133: 971-983. 
Hawkes, C. L., D. L. Miller \& W. G. Layher, 1986. Fish ecoregions of Kansas: Stream fish assemblage patterns and associated environmental correlates. Environmental Biology of Fishes 17: 267-279.

Hawkins, C. P., R. H. Norris, J. N. Hogue \& J. W. Feminella, 2000. Development and use of predictive models for assessing the biological integrity of streams. Ecological Applications 10: 1456-1477.

Hilsenhoff, W. L., 1982. Using a biotic index to evaluate water quality of streams. Technical Bulletin Number 132. Wisconsin Department of Natural Resources, Madison, Wisconsin.

Infante, D. M., M. J. Wiley \& P. W. Seelbach, 2006. Relationships among channel shape, catchment characteristics, and fish In R. M. Hughes, L. Wang \& P. W. Seelbach (eds), Influences of landscapes on stream habitats and biological assemblages. American Fisheries Society, Bethesda, Maryland.

Johnson, R. K. \& W. Goedkoop, 2002. Littoral macroinvertebrate communities: Spatial scale and ecological relationships. Freshwater Biology 47: 1840-1854.

Johnson, L. B., C. Richards, G. E. Host \& J. W. Arthur, 1997. Landscape influences on water chemistry in Midwestern stream ecosystems. Freshwater Biology 37: 193-208.

Karr, J. R., 1991. Biological integrity: A long-neglected aspect of water resource management. Ecological Applications 1: 66-84.

Kilgour, B. W. \& D. R. Barton, 1999. Associations between stream fish and benthos across environmental gradients in southern Ontario, Canada. Freshwater Biology 41: 553-566.

King, R.S., M. E. Baker, D. F. Whigham, D. E. Weller, T. E. Jordan, P. F. Kazyak \& M. K. Hurd, 2005. Spatial considerations for linking watershed land cover to ecological indicators in streams. Ecological Applications 15: 137-153. 
Lammert, M. \& J. D. Allan, 1999. Assessing biotic integrity of streams: Effects of scale in measuring the influence of land use/cover and habitat structure on fish and macroinvertebrates. Environmental Management 23: 257-70.

Lance, G. N. \& W. T. Williams, 1967. A general theory of classificatory sorting strategies: I. Hierarchical Systems. The Computer Journal 9: 373-380.

Legendre, P. \& V. Legendre, 1984. Postglacial dispersal of freshwater fishes in Quebec Peninsula. Canadian Journal of Fisheries and Aquatic Sciences 41: 1781-1802.

Lenat D. R., 1984. Agriculture and stream water quality - a biological evaluation of erosion control practices. Environmental Management 8: 333-343.

Linke, S., R. H. Norris, D. P. Faith \& D. Stockwell, 2005. ANNA: A new prediction method for bioassessment programs. Freshwater Biology 50: 147-158.

Lyons, J., 1992. Using the index of biotic integrity (IBI) to measure environmental quality in warmwater streams of Wisconsin. U. S. Department of Agriculture, Forest Service, North Central Forest Experiment Station, General Technical Report NC-149. St. Paul, Minnesota.

Lyons, J., R. R. Piette \& K. W. Niermeyer, 2001. Development, validation, and application of a fish-based index of biotic integrity for Wisconsin’s large warmwater rivers. Transactions of the American Fisheries Society 130: 1077-1094.

Magalhaes, M. F., D. C. Batalha \& M. J. Collares-Pereira, 2002. Gradients in stream fish assemblages across a Mediterranean landscape: Contributions of environmental factors and spatial structure. Freshwater Biology 47: 1015-1031.

McCune, B. \& J. Mefford, 1997. PC-ORD. Multivariate analysis of ecological data. Mjm Software Design, Gleneden Beach, Oregon. 
Meador, M. R. \& R. M. Goldstein, 2003. Assessing water quality at large geographic scales:

Relations among land use, water physicochemistry, riparian condition, and fish community structure. Environmental Management 31: 504-517.

Michigan Department of Environmental Quality, 1997. Qualitative biological and habitat survey protocols for wadeable streams and rivers. MI/DEQ/SWQ-96/068. Surface Water Quality Division. Great Lakes Environmental Assessment Section. Staff Report.

Michigan Resource Information System (MIRIS), 1978. Michigan land use (geographic information system maps). Michigan Department of Natural Resources, Lansing, Michigan.

Norris, R. H. \& A. Georges, 1993. Analysis and interpretation of benthic macroinvertebrate surveys In D. M. Rosenberg and V. H. Resh (eds), Freshwater biomonitoring and benthic macroinvertebrates. Chapman and Hall, New York.

Norris, R. H. \& C. P. Hawkins, 2000. Monitoring river health. Hydrobiologia 435: 5-17.

Olden, J. A. \& N. L. Poff, 2004. Ecological processes driving biotic homogenization: Testing a mechanistic model using fish faunas. Ecology 85: 1867-1875.

Osborne, L. L. \& M. J. Wiley, 1988. Empirical relationship between land-use cover and stream water quality in an agricultural watershed. Journal of Environmental Management 26: 927.

Paavola, R., T. Muotka, R. Virtanen, J. Heino, D. Jackson \& A. Maki-Petays, 2006. Spatial scale affects community concordance among fishes, benthic macroinvertebrates, and bryophytes in streams. Ecological Applications 16: 368-379. 
Paavola, R., T. Muotka, R. Virtanen, J. Heino \& P. Kreivi, 2003. Are biological classifications of headwater streams concordant across multiple taxonomic groups? Freshwater Biology 48: $1912-1923$.

Paszkowski, C. A \& W. M. Tonn, 2000. Community concordance between the fish and aquatic birds of lakes in northern Alberta, Canada: The relative importance of environmental and biotic factors. Freshwater Biology 43: 421-437.

Podani, J., 1997. On the sensitivity of ordination and classification methods to variation in the input order of data. Journal of Vegetation Science 8: 153-156.

Poff, N. L., 1997. Landscape filters and species traits: Towards mechanistic understanding and prediction in stream ecology. Journal of the North American Benthological Society 16: 391-409

Poff, N. L. \& J. D. Allan, 1995. Functional organization of stream fish assemblages in relation to hydrologic variability. Ecology 76: 606-627.

Quinn, J. M. 2000. Effects of pastoral development In K. J. Collier \& M. J. Winterbourn (eds), New Zealand stream invertebrates: Ecology and implications for management. Caxton Press, Christchurch, New Zealand.

Quist, M. C., F. J. Rahel \& W. A. Hubert, 2005. Hierarchical faunal filters: An approach to assessing effects of habitat and nonnative species on native fishes. Ecology of Freshwater Fish 14: 24-39.

Richards, C., L. B. Johnson \& G. E. Host, 1996. Landscape-scale influences on stream habitats and biota. Canadian Journal of Fisheries and Aquatic Sciences 53: 295-311.

Rios, S. L. \& R. C. Bailey, 2006. Relationship between riparian vegetation and stream benthic communities at three spatial scales. Hydrobiologia 553: 153-160. 
Infante et al.

Roth, N. E., J. D. Allan \& D. L. Erickson, 1996. Landscape influences on stream biotic integrity assessed at multiple spatial scales. Landscape Ecology 11: 141-156.

Schlosser, I. J., 1995. Critical landscape attributes that influence fish population dynamics in headwater streams. Hydrobiologia 303: 71-81.

Scott, M. C. \& G. S. Helfman, 2001. Native invasions, homogenization, and the mismeasure of integrity of fish assemblages. Fisheries 26: 6-15.

Sneldor, T. H. \& B. J. F. Biggs, 2002. Multiscale river environment classification for water resources management. Journal of the American Water Resources Association 38: 12251239.

Sponseller, R. A., E. F. Benfield, \& H. M. Valett, 2001. Relationships between land use, spatial scale and stream macroinvertebrate communities. Freshwater Biology 46: 1409-1424.

Stewart, J. S., L. Wang, J. Lyons, J. A. Horwatich \& R. Bannerman, 2001. Influences of watershed, riparian-corridor, and reach-scale characteristics on aquatic biota in agricultural watersheds. Journal of the American Water Resources Association 37: 14751487.

Tonn, W. M., J. J. Magnuson, M. Rask \& J. Toivonen, 1990. Intercontinental comparison of small-lake fish assemblages: The balance between local and regional processes. The American Naturalist 136: 345-375.

Townsend, C. R., S. Doledec, R. H. Norris, K. Peacock \& C. J. Arbuckle, 2003. The influence of scale and geography on relationships between stream community composition and landscape variables: Description and prediction. Freshwater Biology 48: 768-785.

Vannote, R. L., G. W. Minshall, K. W. Cummins, J. R. Sedell \& C. E. Cushing, 1980. The river continuum concept. Canadian Journal of Fisheries and Aquatic Sciences 37: 130-137. 
Infante et al.

Van Sickle, J. \& R. M. Hughes, 2000. Classification strengths of ecoregions, catchments, and geographic clusters for aquatic vertebrates in Oregon. Journal of the North American Benthological Society 19: 370-384.

Vieira, N. K. M., N. L. Poff, D. M. Carlisle, S. R. Moulton, M. L. Koski \& B. C. Kondratieff, 2006. A database of lotic invertebrate traits for North America: U.S. Geological Survey Data Series 187. U.S. Department of the Interior, Reston, Virginia. (Available from: http://pubs.usgs.gov/ds/ds187/).

Wang, L., J. Lyons, P. Kanehl \& R. Gatti, 1997. Influences of watershed land use on habitat quality and biotic integrity in Wisconsin streams. Fisheries 22: 6-12.

Wang, L., J. Lyons \& P. Kanehl, 2001. Impacts of urbanization on stream habitat and fish across multiple spatial scales. Environmental Management 28: 255-266.

Wang, L., J. Lyons, P. Rasmussen, P. Seelbach, T. Simon, M. Wiley, P. Kanehl, E. Baker, S. Niemela \& P. M. Stewart, 2003. Watershed, reach and riparian influences on stream fish assemblages in the Northern Lakes and Forest Ecoregion, U.S.A. Canadian Journal of Fisheries and Aquatic Science 60: 491-505.

Walters, D. M., D. S. Leigh \& A. B. Bearden, 2003. Urbanization, sedimentation, and the homogenization of fish assemblages in the Etowah River Basin, U.S.A. Hydrobiologia 494: 5-10.

Whittier, T. R., R. M. Hughes \& D. P. Larsen, 1988. Correspondence between ecoregions and spatial patterns in stream ecosystems in Oregon. Canadian Journal of Fisheries and Aquatic Sciences 45: 1264-1278.

Wright, J. F., 1995. Development and use of a system for predicting the macroinvertebrate fauna in flowing waters. Australian Journal of Ecology 20: 181-197. 
Infante et al.

Wood, M. G. S., 2002. The influence of land cover and in-stream habitat on the biological condition of streams in southeastern Michigan. M.S. Thesis, University of Michigan, Ann Arbor, Michigan.

Yoder, C. O. \& E. T. Rankin, 2004. Trends in biological integrity, biodiversity and aquatic habitat in the Eastern Corn Belt Plains Ecoregion: Implications for the protection and restoration of streams in the St. Joseph River Watershed. Executive Summary for the Midwest Biodiversity Institute. Aquatic Life Use Fact Sheet 1-MBI-03. Columbus, Ohio. 


\section{Figure Captions}

Figure 1. Location of the Huron and Raisin River Basins and 46 study catchments in southeastern Michigan, U.S.A.

Figure 2. Box-and-whisker plots showing taxa richness arranged from highest to lowest median values for each macroinvertebrate (a) and fish (b) group.

Figure 3. Box-and-whisker plots showing relative abundance of organisms with low tolerance to stressors arranged from highest to lowest median values for each macroinvertebrate (a) and fish (b) group.

Figure 4. Differences in macroinvertebrate habitat preferences (a) and trophic guilds (b) by groups. Y-axes indicate relative abundance (\%) of macroinvertebrates in each functional category averaged across site groups.

Figure 5. Differences in fish trophic guilds (a), channel unit (b), and substrate preferences (c) by groups. Y-axes indicate relative abundance (\%) of fish in each functional category averaged across site groups. 


\section{Table Headings}

Table 1. Taxa identified by Principal Axis Correlation as significantly $(\mathrm{p} \leq 0.005)$ associated with variation in macroinvertebrate assemblages. Included are each taxon's average relative abundance in each site group, and taxa are sorted to indicate sets of organisms with highest average abundances per group.

Table 2. Site group average values of physical variables identified by PCC as significantly associated with variation in macroinvertebrate assemblages $(\mathrm{p} \leq 0.05)$.

Table 3. Species identified by Principal Axis Correlation as significantly $(\mathrm{p} \leq 0.05)$ associated with variation in fish assemblages. Included are each species' average relative abundance in each site group, and species are sorted to indicate sets of organisms with highest average abundances per group.

Table 4. Site group average values of physical variables identified by PCC as significantly associated with variation in fish assemblages $(\mathrm{p} \leq 0.05)$.

Table 5. Site overlap between each fish and macroinvertebrate group. Results are ordered to reflect ranges in group average values for land use and surficial geology for comparison of fish and macroinvertebrate groups sharing similar landscape characteristics. 
Infante et al.

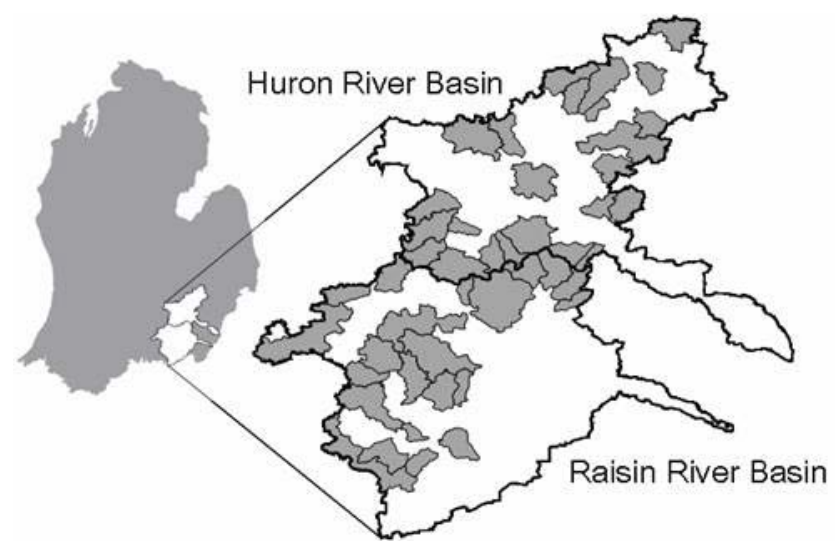

Figure 1. 
Infante et al.

(a)

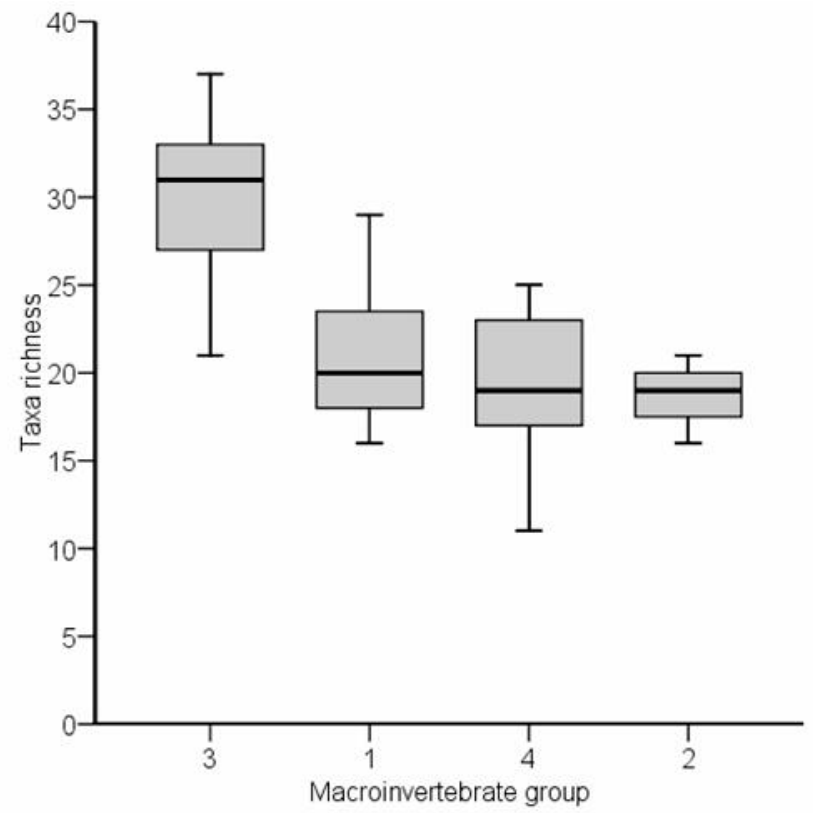

(b)

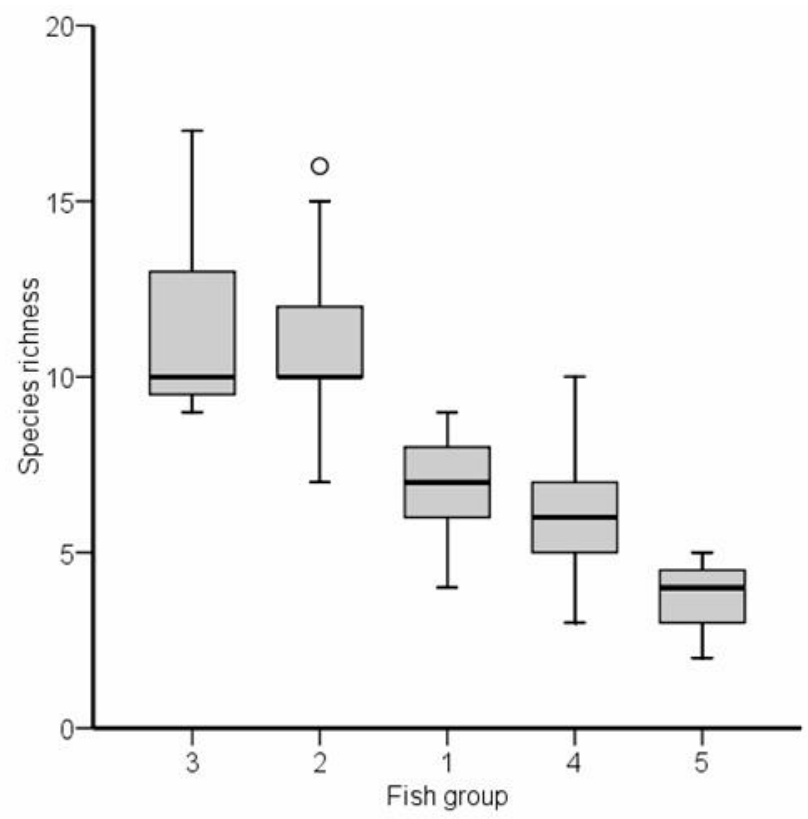

Figure 2. 
Infante et al.

(a)

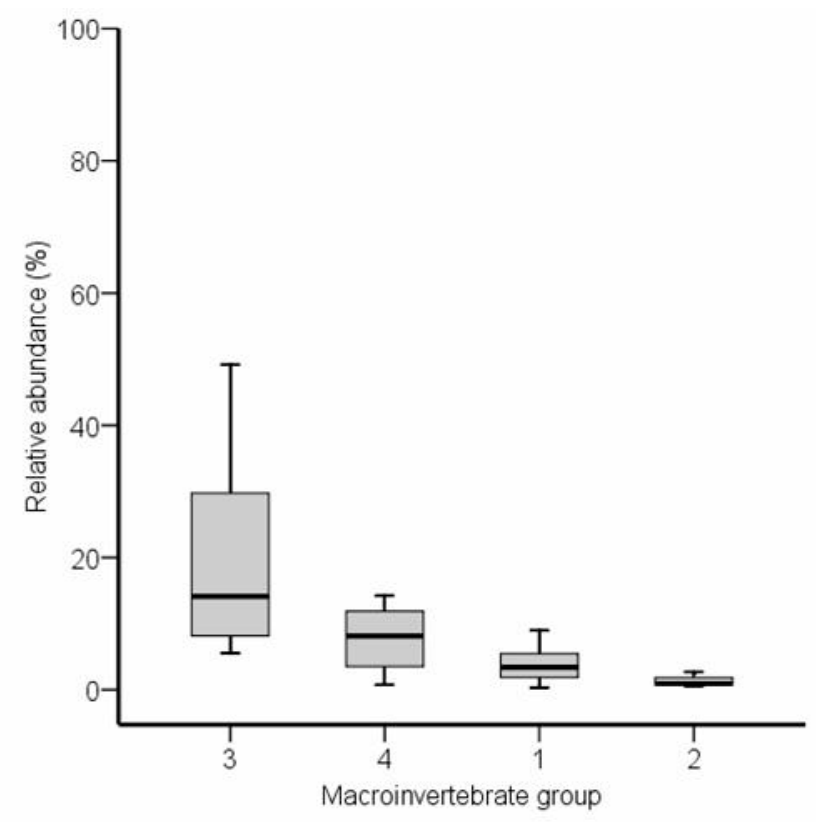

(b)

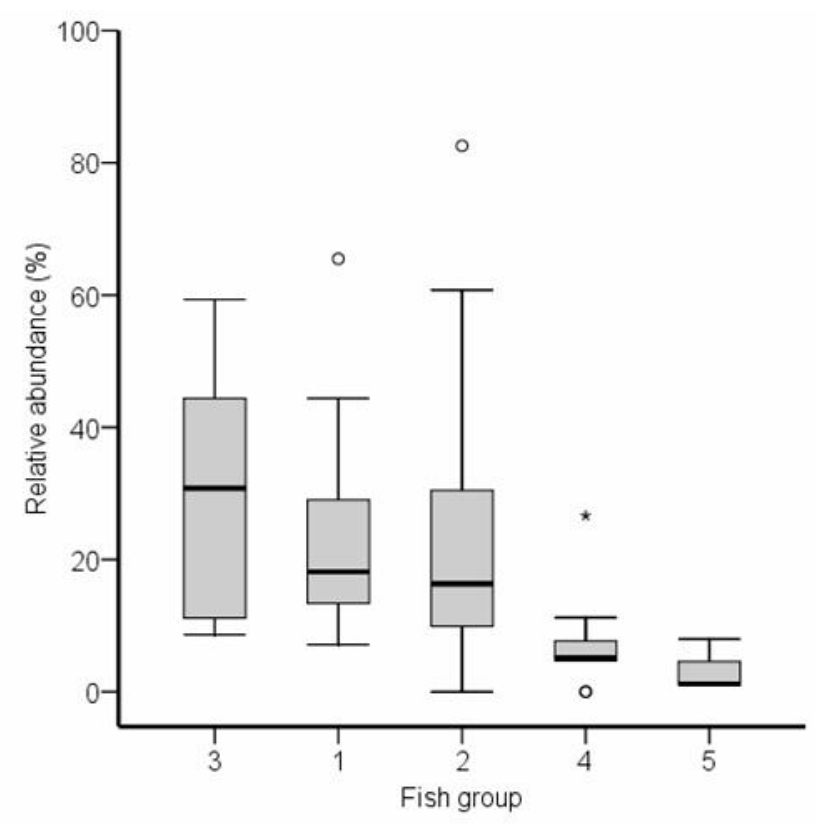

Figure 3. 
(a)

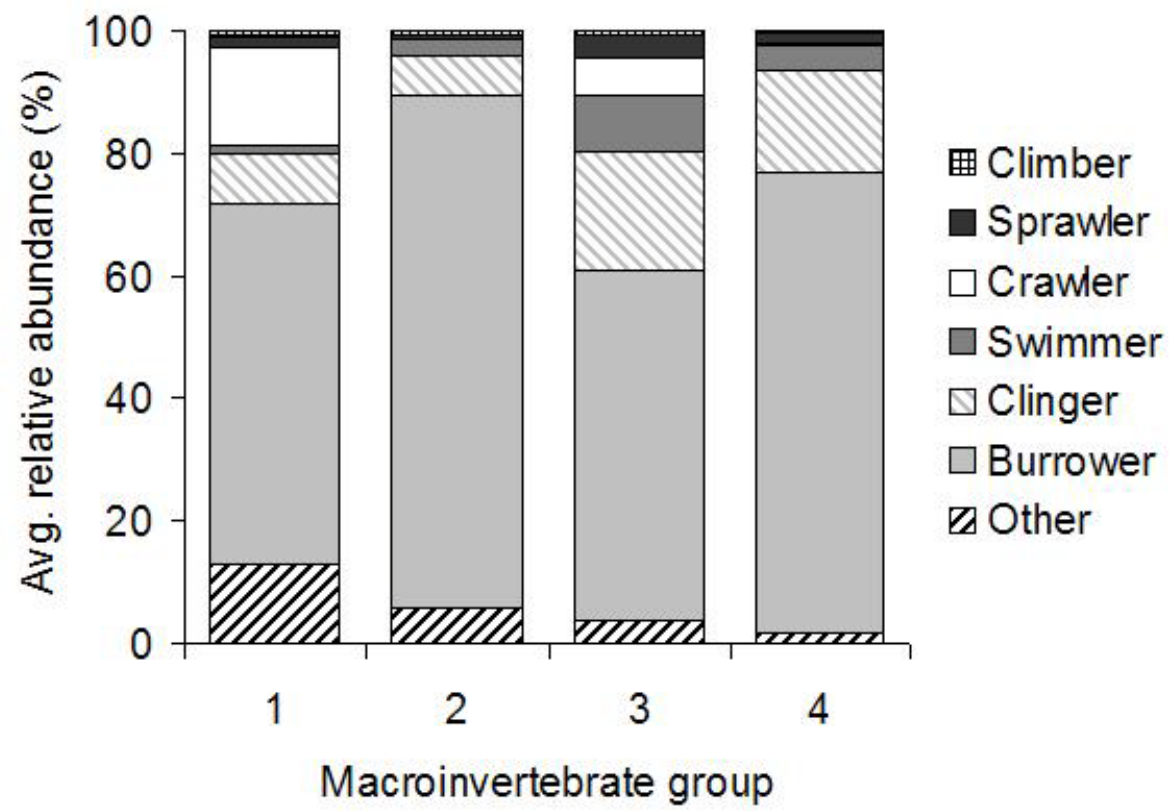

(b)

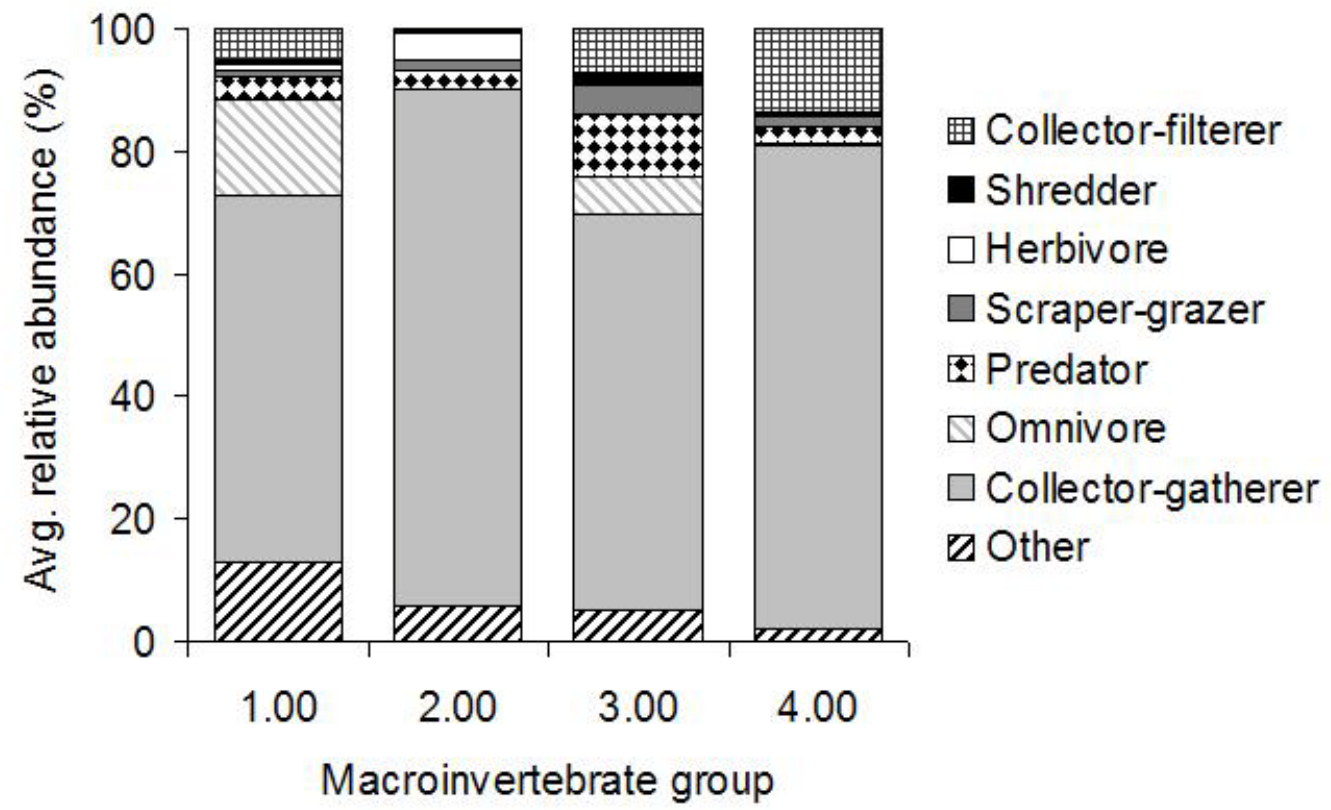

Figure 4. 
Infante et al.

(a)

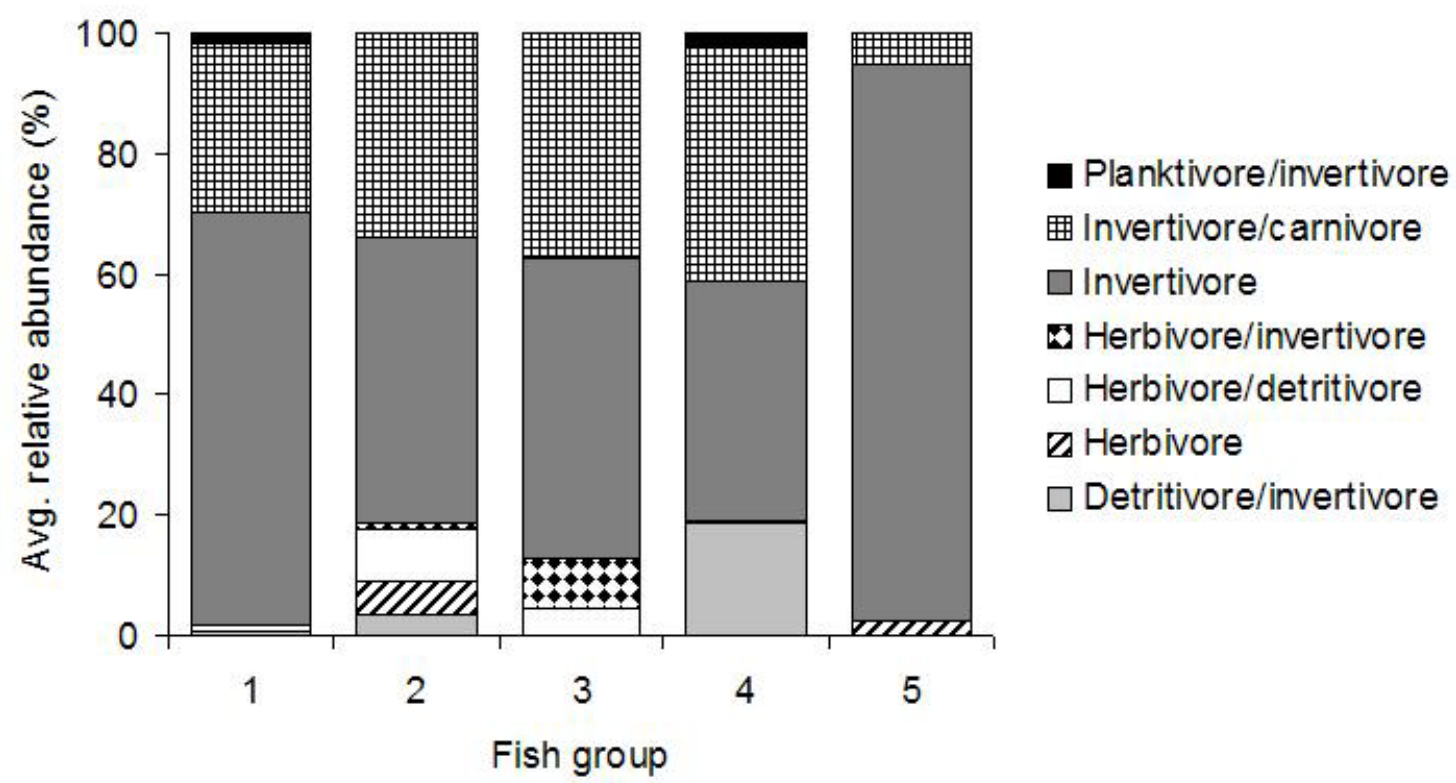

(b)

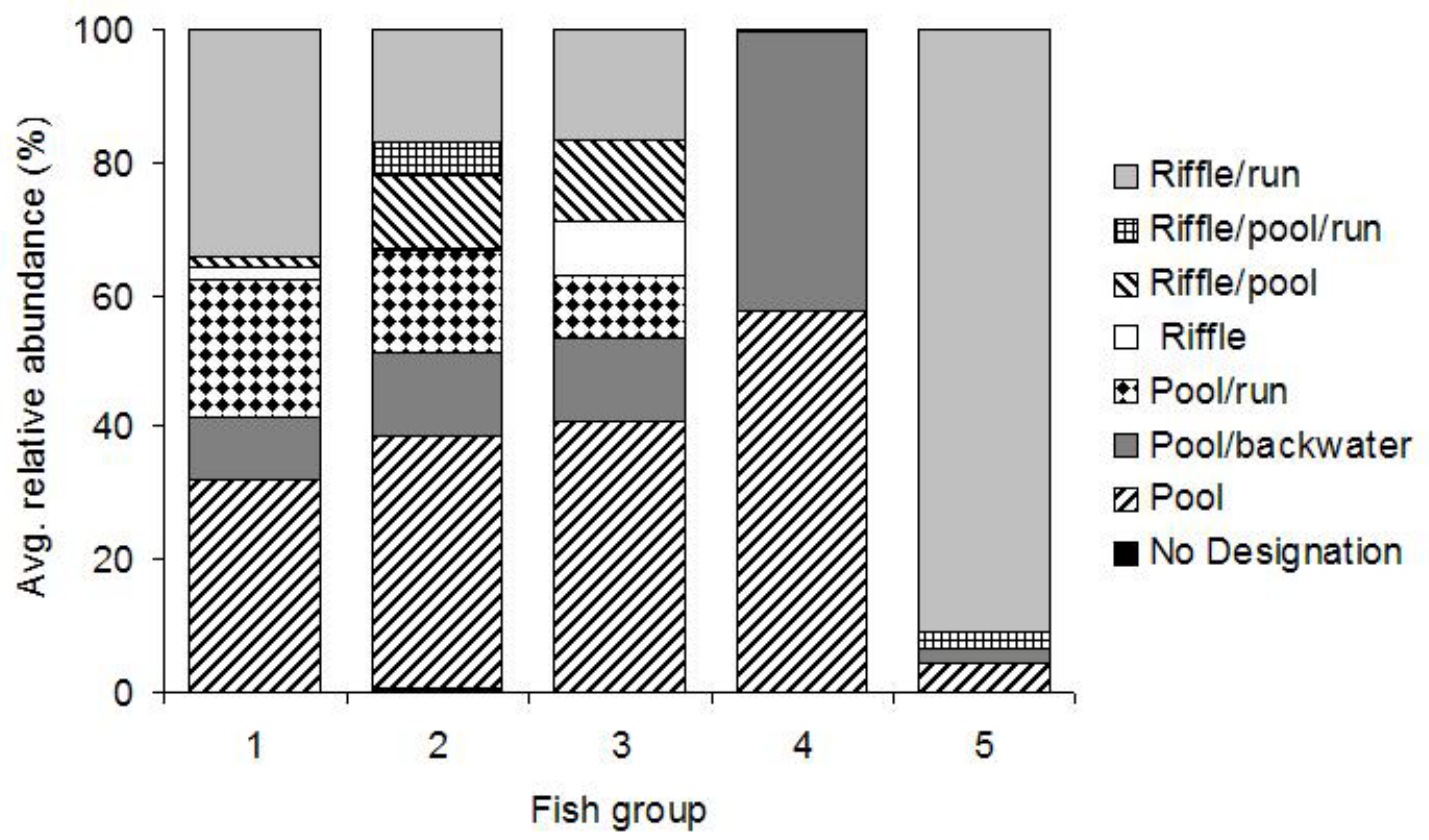


Infante et al.

(c)

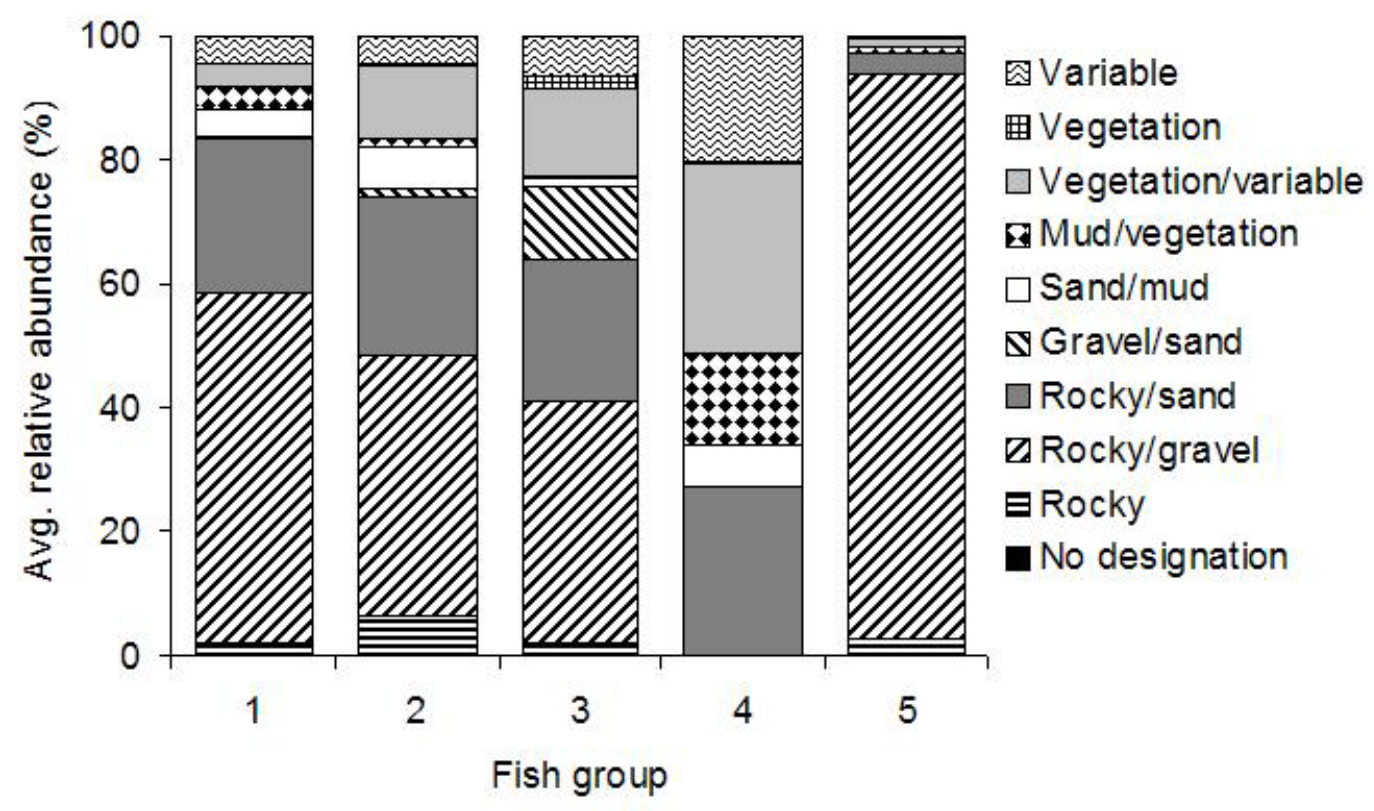

Figure 5. 
Table 1.

\begin{tabular}{|c|c|c|c|c|c|c|}
\hline \multirow[b]{2}{*}{ Order } & \multirow[b]{2}{*}{ Family } & \multirow[b]{2}{*}{ Genus } & \multicolumn{4}{|c|}{ Group average relative abundance (\%) } \\
\hline & & & 1 & 2 & 3 & 4 \\
\hline Amphipoda & Gammaridae & Gammarus & 15.65 & 0.04 & 5.89 & 0.30 \\
\hline Bivalva & & & 0.89 & & 0.24 & 0.04 \\
\hline Odonata & Coenagrionidae & Enallagma & 0.14 & 0.13 & 0.03 & \\
\hline Oligochaeta & & & 10.61 & 4.14 & 2.04 & 1.30 \\
\hline Coleoptera & Elmidae & Dubiraphia & 0.81 & 4.26 & 0.35 & 0.07 \\
\hline Diptera & Ceratopogonidae & & 0.31 & 1.20 & 0.20 & 0.11 \\
\hline Diptera & Chironomidae & & 57.71 & 82.37 & 55.34 & 74.43 \\
\hline Gastropoda & & & 0.75 & 1.17 & 0.10 & 0.19 \\
\hline Odonata & Calopterygidae & Colopteryx & 0.38 & 0.59 & 0.19 & 0.17 \\
\hline Coleoptera & Elmidae & Stenelmis & 0.27 & 0.08 & 2.11 & 0.53 \\
\hline Coleoptera & Scirtidae & Scirtes & 0.13 & & 0.24 & \\
\hline Diptera & Tabanidae & Crysops & 0.41 & 0.24 & 1.39 & 0.36 \\
\hline Diptera & Tipulidae & Pseudolimnophila & 0.05 & & 0.81 & 0.14 \\
\hline Diptera & Tipulidae & Tipula & 0.04 & & 0.09 & 0.01 \\
\hline Ephemeroptera & Baetidae & Baetis & 0.84 & 0.22 & 8.16 & 3.38 \\
\hline Ephemeroptera & Heptageniidae & Stenonema & 0.02 & 0.24 & 0.55 & 0.12 \\
\hline Plecoptera & Nemouridae & Amphinemura & 0.08 & & 0.93 & 0.09 \\
\hline Plecoptera & Perlidae & Perlesta & 0.07 & & 1.24 & 0.07 \\
\hline Trichoptera & Hydropsychidae & Ceratopsyche & 0.07 & & 0.70 & \\
\hline Trichoptera & Hydropsychidae & Cheumatopsyche & 0.64 & & 0.98 & 0.94 \\
\hline Trichoptera & Hydropsychidae & Hydropsyche & 0.15 & 0.08 & 0.56 & 0.16 \\
\hline Trichoptera & Philopotamidae & Chimarra & 0.01 & & 0.29 & \\
\hline Diptera & Simuliidae & Simulium & 4.12 & 0.38 & 4.11 & 12.03 \\
\hline
\end{tabular}


Table 2.

\begin{tabular}{llcccc}
\hline & & \multicolumn{3}{c}{ Group average value } \\
\cline { 2 - 5 } Variable category & Variable & 1 & 2 & 3 & 4 \\
\hline Channel shape & Channel incision (m) & 0.37 & 0.48 & 0.29 & 0.48 \\
Visual habitat assessment & Embeddedness/siltation & 10.0 & 7.3 & 13.6 & 8.9 \\
& Velocity/depth variability & 11.0 & 9.0 & 13.6 & 10.1 \\
& Flow stability & 7.7 & 4.7 & 9.1 & 7.2 \\
& Pools, riffles, runs, bends & 6.9 & 6.3 & 9.2 & 7.0 \\
& Bank stability & 5.9 & 2.7 & 6.1 & 4.2 \\
Natural landscape & Bank vegetative stability & 7.5 & 5.0 & 7.6 & 6.2 \\
& Slope & 0.0022 & 0.0024 & 0.0030 & 0.0023 \\
Catchment land use & Coarse surficial geology (\%) & 51.13 & 4.10 & 62.98 & 20.64 \\
& Fine surficial geology (\%) & 39.20 & 95.90 & 20.39 & 47.04 \\
& Nonforested wetlands (\%) & 13.45 & 9.31 & 17.93 & 12.98 \\
Buffer land use & Wetlands (\%) & 10.48 & 3.95 & 13.63 & 5.91 \\
& Undeveloped lands (\%) & 33.98 & 21.92 & 43.48 & 29.58 \\
& Undeveloped lands (\%) & 47.02 & 38.10 & 61.62 & 47.40 \\
\hline
\end{tabular}


Infante et al.

Table 3.

\begin{tabular}{|c|c|c|c|c|c|c|c|}
\hline \multirow[b]{2}{*}{ Family } & \multirow[b]{2}{*}{ Genus } & \multirow[b]{2}{*}{ Species } & \multicolumn{5}{|c|}{ Group average relative abundance (\%) } \\
\hline & & & 1 & 2 & 3 & 4 & 5 \\
\hline Cyprinidae & Rhinichthys & atratulus & 20.48 & 14.44 & & & \\
\hline Percidae & Etheostoma & nigrum & 4.61 & 6.36 & 1.60 & 1.33 & \\
\hline Cyprinidae & Campostoma & anomalum & 0.08 & 5.25 & & & 2.66 \\
\hline Cyprinidae & Luxilus & cornutus & & 0.92 & 9.21 & & \\
\hline Centrarchidae & Lepomis & macrochirus & 2.31 & 5.34 & 11.76 & 23.72 & 0.40 \\
\hline Centrarchidae & Lepomis & gibbosus & 0.56 & 0.53 & 1.01 & 2.66 & \\
\hline Cottidae & Cottus & bairdi & 34.28 & 16.07 & 11.34 & 0.00 & 91.08 \\
\hline
\end{tabular}


Table 4.

\begin{tabular}{llccccc}
\hline & & \multicolumn{4}{c}{ Group average value } \\
\cline { 2 - 6 } Variable category & Variable & 1 & 2 & 3 & 4 & 5 \\
\hline Channel shape & Channel fit & 1.52 & 1.42 & 1.26 & 1.38 & 1.99 \\
Visual habitat assessment & Pools, riffles, runs, bends & 6.8 & 8.3 & 9.7 & 7.3 & 5.3 \\
& Bank stability & 5.1 & 4.9 & 6.6 & 6.2 & 4.3 \\
Natural landscape & Coarse geology & 36.52 & 31.98 & 88.18 & 61.67 & 28.33 \\
Catchment land use & Agriculture (\%) & 47.95 & 55.49 & 20.94 & 31.25 & 51.63 \\
Buffer land use & Agriculture (\%) & 34.29 & 45.96 & 9.02 & 19.28 & 34.84 \\
\hline
\end{tabular}


Infante et al.

Table 5.

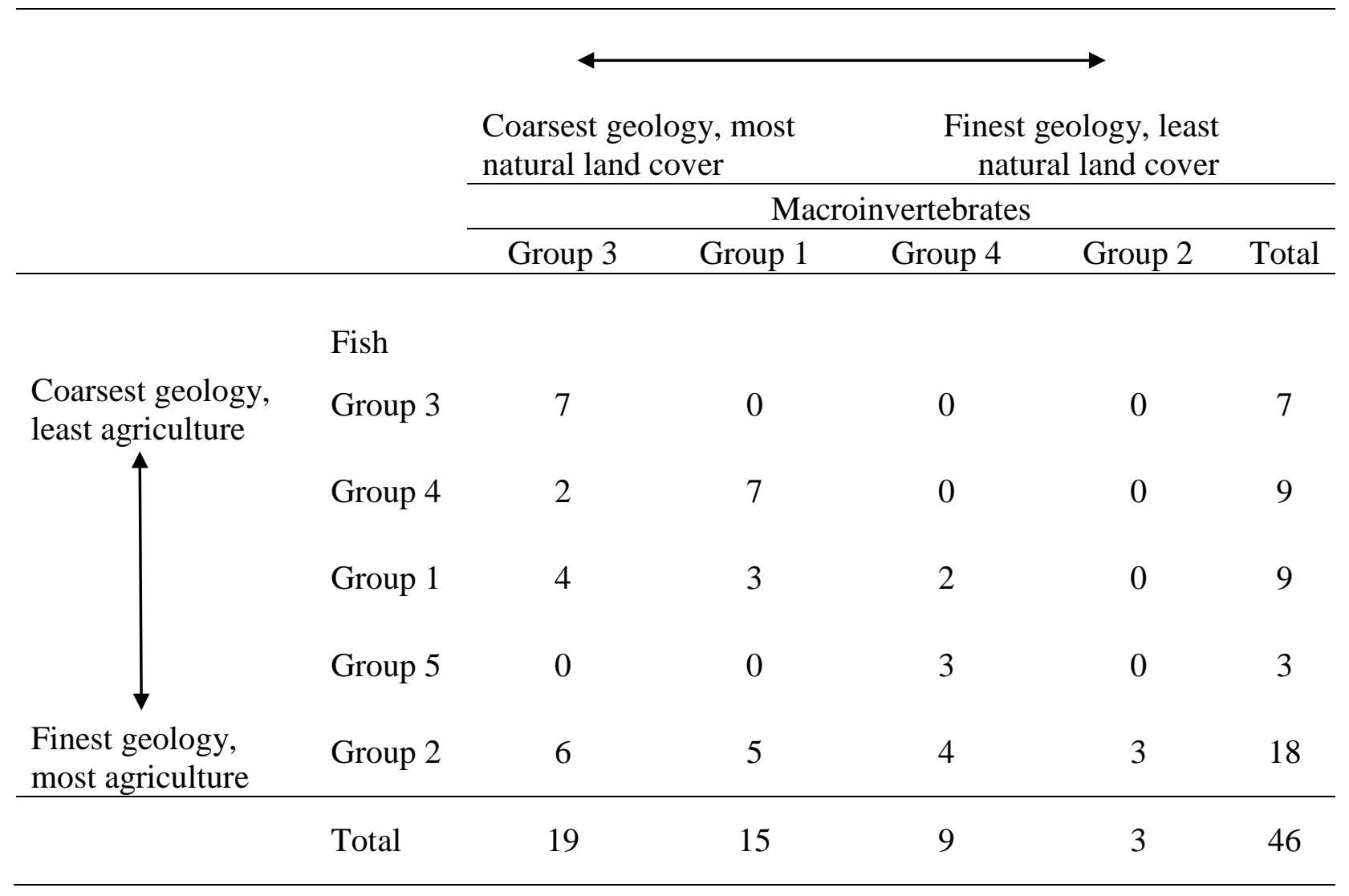

